filter ash had been subtracted. This experiment was also repeated with similar results, proving the purity from silica of the lead sulphate precipitate.

We believe the foregoing experiments test the method fairly and rigidly, and that chemists will be safe in using the above when they know metals precipitated by sulphuric acid as sulphates or oxidized by nitric acid to insoluble compounds are absent.

Barium and strontium are rarely found associated with lead. Calcium, when present in galena as calcite, may be gotten rid of by first treating the ore with hydrochloric acid and filtering. The filtrate will contain the calcium ; the residue will hold the lead and may be treated with hydrofluoric, sulphuric, and nitric acids, and the process carried out as above.

When the ore contains calcium, in small quantities only, the latter may be hindered from interfering with accurate results by washing the precipitated lead sulphate four or five times by decantation and then thoroughly upon the filter with a two per cent. solution of sulphuric acid. The calcium sulphate, being slightly soluble in the acid solution, is carried off by the wash water. The writer has found it possible to remove as much as four per cent. of calcium sulphate by this means.

The analysis of a lead ore can be made very nearly as quickly by this method as volumetrically and much more satisfactorily.

CHEMICAL LABORATORY, LONGDALE IRON CO.,

LONGDALE, ALLEGHANY Co., VirgiNia.

\title{
NOTE ON THE SEPARATION OF SILICIC AND TUNGSTIC ACIDS.
}

BY JAMES S. DE BENNEVILLE.

Recelved March 20, 1897.

THE object of the present note is to call attention to an important observation made by $\mathrm{Mr}$. Lawrence Dufty in reference to the determination of silicon in tungsten steel and ferrotungsten. A common method for making such determination is to dissolve the tungstic oxide on the filter by means of hot dilute ammonia and to so obtain the silica at once for determination. Karsten' had pointed out the solubility of freshly pre-

1 Ann. der Phys. (Pogg.), 6, 357, 3826. 
cipitated silicicacid in ammonia, and Pribram 'and later Sonchay ${ }^{2}$ had shown that even ignited amorphous silica was perceptibly soluble in this alkaline reagent. Mr. Dufty ${ }^{3}$ showed that in dealing with the small quantities of silicon found in ferrotungsten and in tungsten steels this solubility of the silica renders the ammonia method incorrect and misleading. To his results, as given by Professor Arnold, it can be added that the remarks apply equally well to cold ammonia. Solution of ore or alloy, evaporation to dryness, re-solution and filtration of the mixed oxides from the soluble material is conducted in the usual manner. The experimental results given in Tables I and II were obtained with a ferromanganese containing nearly seven per cent. of tungsten. In the figures given, the solubility of the silica is not so great as compared with Mr. Dufty's results. If the residue, dried on the center of the store, is burnt over the naked flame, this solubility is still further reduced; but in such case the quantity of tungstic oxide insoluble in ammonia is greater than when the residue is simply baked. Also, evaporation with hydrofluoric acid alone does not cause any loss of tungsten; but the addition of a few drops of sulphuric acid apparently insures the complete expulsion of the silica more readily than when hydrofluoric acid is used alone. The advantage, therefore, of weighing the total oxides and volatilizing the silica, as recommended by Professor Arnold, is obvious. In mineral analysis, and particularly in the preparation of pure tungstic oxide, the reaction of silica with ammonia is an important one; for only the crystallized ammonium tungstate is free from silica. A wolframite containing 65.5 per cent. tungsten trioxide, and by the volatilization method 5.6I per cent. silica, gave on dissolving the tungstic oxide from silica by ammonia ( $I$ ) insoluble silica 3.84 per cent., and soluble silica r.64 per cent., and (2) insoluble silica 3.22 per cent. and soluble silica 2.20 per cent. The silica belongs mainly to intermixed mica.

1 Ztschr, anal. Chem. (Abstract), 6, I19, 8867.

2 Jbid, I1, I82, 1872 .

3 Cited by Professor'T. O. Arnold: "Stee1 Works Analysis," pp. 136-1 $3^{8}$. Whittaket \& Co., Loudon, I895. 
FFRROMANGANESE CONTAINING TUNGSTEN.

I. Residue Baked to Dust Dryness on the Stove.

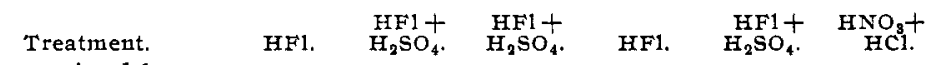

Silica regained by one

$\begin{array}{lllllll}\text { evaporation...... } & 0.0040 & 0.0022 & 0.0059 & 0.0038 & 0.0035 & \ldots\end{array}$

Silica regained by two

$\begin{array}{llllllllll}\text { evaporations } & \ldots & 0.0058 & 0.0024 & 0.0057 & 0.0049 & 0.0036 & \ldots\end{array}$

Silica regained by three evaporations .... 0.0065

Silica regained by four

evaporatious $\ldots . .0 .0062$

Total silicon regained 0.0030

Per cent. total silicon $\cdot 21.7$

Total silicon in the

alloy $. . \ldots \ldots \ldots, 0.0139$

$\begin{array}{llll}0.0022 & 0.0055 & 0.005 \text { I } & 0.0036\end{array}$

$\begin{array}{lcccc}\ldots . & \ldots \ldots & 0.0055 & \ldots . & \ldots \\ 0.0010 & 0.0026 & 0.0026 & 0.0017 & \ldots \\ 7.0 & 19.0 & 18.2 & 12.8 & \ldots\end{array}$

$\begin{array}{lllll}0.0141 & 0.0137 & 0.0143 & 0.0133 & 0.014 I\end{array}$

II. Residue Burnt over the Flame.

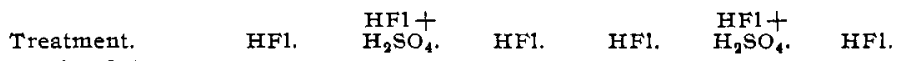

Silica regained by one

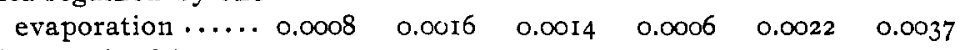

Silica regained by two

$\begin{array}{llllllll}\text { evaporations } & \cdots & 0.0010 & 0.0016 & 0.0020 & 0.0004 & 0.0024 & 0.0037\end{array}$

Silica reg'n'd by three

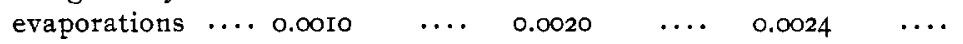

Silica regained by four

evaporations .... 0.0009

Total silicon regained 0.0005

Per cent. total silicon 3.62

Total silicon in the
alloy ........... 0.0138

0.0007

0.0022

5.11

0.0010

0.0003

$0.001 \mathrm{I}$

0.0017

$\begin{array}{llll}0.0137 & 0.0145 & 0.0142 & 0.0136\end{array}$

In both tables the figures refer to the silica recovered from the ignited tungstic oxide which has been "separated" by digestion with cold ammonia solution.

\section{THE ELECTROLYTIC DETERMINATION OF CADMIUM.'}

BY S. AVERY AND BENTON DALES.

Received March 23, 1897,

T

$\mathrm{HE}$ work here presented grew out of an effort to find a practical method for determining this metal. The usual methods often fail to give satisfactory results, and, while we have not succeeded in finding an ideal method, we hope that the experiments here given will be of interest.

1 Read at the meeting of the Nebraska Section, March I9, I897. 